\title{
Why and how is the self-related to the brain midline regions?
}

\author{
Pengmin Qin*, Niall Duncan and Georg Northoff \\ Mind, Brain Imaging and Neuroethics, University of Ottawa Institute of Mental Health Research, Ottawa, ON, Canada \\ ${ }^{*}$ Correspondence: pengmin.qin@theroyal.ca \\ Edited by: \\ Hauke R. Heekeren, Freie Universität Berlin, Germany
}

Keywords: self, cortical midline structure, resting state, patients with disorders of consciousness, mental disorders

What the self is and where it comes from has been one of the great problems of philosophy for thousands of years. As science and medicine have progressed this question has moved to also become a central one in psychology, psychiatry, and neuroscience. The advent of in vivo brain imaging has now allowed the scientific investigation of the self to progress further than ever.

Many such imaging studies have indicated that brain structures along the cortical midline are particularly closely related to self-specific processing. This association between cortical midline structures (CMS) and self is reinforced by the involvement of these regions in other self-oriented processes, such as mind-wandering or stimulus valuation. Those midline regions involved in selfprocessing also overlap with another network, the default mode network, which shows high brain activity during the so-called resting state, indicating that there may be a special relationship between self-processing and intrinsic activity.

Although such promising groundwork linking the self and CMS has been carried out, many questions remain. These include: what features of the midline regions lead to their apparent importance in self-processing? How can we appropriately account for confounding factors such as familiarity or task-effects in our experiments? How is the self-related to other features of the mind, such as consciousness? How is our methodology influencing our attempts to link the self and the brain?

The purpose of this ebook is to address some of these questions, including opinions, perspectives, and hypotheses about the concept of the self, the relationship between CMS and the self, and the specific function of these brain regions in self-processing. It also includes original research papers describing EEG, fMRI, and behavioral experiments investigating different aspects of the self.

The included papers can be roughly divided into four groups as follows: the first group of papers both collate existing evidence that midline structures are involved in self-processing and produce evidence for new facets of it. Reviewing the literature, Knyazev (2013) provides an overview of existing EEG studies of self-related activity, highlighting an overlap between self-related activity and rest, as well as the apparent importance of the P300 ERP and alpha activity in self-processing. Similarly, Araujo et al. (2013) present a meta-analysis of imaging studies that associates the medial prefrontal cortex (mPFC) with self-traits, in contrast to posterior regions which are more associated with the traits of others. In an fMRI study, Qin et al. (2013) show that self-related stimuli interact differently with intrinsic activity in the auditory cortex than do non-self-related. This finding provides backing for the hypotheses that self and intrinsic activity are particularly related. Looking at how self-trait priming affects task-performance, Bengtsson and Penny (2013) present experimental results and a Bayesian computation model for the effects observed. Finally, Colton et al. (2013) use fMRI to show that age-related trait stimuli activate midline regions and that this interacts with subject age, highlighting the importance of contextual information for self-related processing.

The second group of papers describes existing evidence for the different functions of the separate midline regions. Focusing on the mPFC, both D'Argembeau (2013) and Abraham (2013) discuss this region's role in the assignment of personal value or significance to self-related stimuli. Switching to the posterior midline regions, Brewer et al. (2013) review the literature relating to the role of the posterior cingulate cortex (PCC). They use this to present the idea that the PCC may be involved in the experience of being engaged with mental content. The PCC, as part of the DMN, is also discussed, along with mirror neurons, by Molnar-Szakacs and Uddin (2013) in their discussion of the role of CMS in self-relevant and social processing, suggesting a key role for them in embodiment and simulation. Also considering the role of midline regions in social cognition, Flagan and Beer (2013) discuss the mPFC and the social self, describing how different sub-regions may be involved in different aspects of self-evaluation.

Alterations of self are seen in many mental disorders, as well as in disorders of consciousness (DOC) - the focus of the third group. Crone et al. (2013) present an fMRI study of the response to self/other names in CMS of patients with DOC, adding to the literature on self in such conditions, as reviewed here by Demertzi et al. (2013). Early life stress is associated with a higher risk of mental disorders in later life - in a NIRS study Nakao et al. (2013) show that it is also correlated with changes in resting and selfrelated activity in the $\mathrm{mPFC}$, with possible effects on how people make decisions. This finding fits in with many prior ones of a change in midline structure activity in mental disorders, such as depression, autism, or borderline personality disorder, as reviewed here by Zhao et al. (2013) and Nejad et al. (2013).

Finally, the fourth group provides analysis of the different concepts involved in the study of the self and discusses how these can be related to the brain. This is important for good experimental design and interpretation. This point is made by Sandrone (2013) in their perspective paper, suggesting also that a consideration of 
the mirror neuron system is also needed. Also important is how we interpret the term "self," a point made by Musholt (2013), who differentiates being a subject of conscious experience and being aware of oneself as such. Considering different relationships between midline regions and the self, Moran et al. (2013) puts forward three different aspects - thinking about people, binding stimuli, and directing thought - and discuss how these may be related to the mPFC. Finally models of how we may think about the self are presented by Sugiura (2013), advocating a forward processing model for considering different aspects of the self, and Gallagher (2013), who presents a concept of the self that sees it as an altering pattern of properties.

In summary, this ebook presents recent findings about the relationship between CMS and self-processing, and provides novel hypotheses and interpretations of these findings. Simultaneously, the "blind-spots" of current research, as well as new ideas about self-processing, are mentioned. Together, these papers may throw light on new directions for investigating the self.

\section{REFERENCES}

Abraham, A. (2013). The World according to me: personal relevance and the medial prefrontal cortex. Front. Hum. Neurosci. 7:341. doi:10.3389/fnhum.2013.00341

Araujo, H. F., Kaplan, J., and Damasio, A. (2013). Cortical midline structures and autobiographical-self processes: an activation-likelihood estimation metaanalysis. Front. Hum. Neurosci. 7:548. doi:10.3389/fnhum.2013.00548

Bengtsson, S. L., and Penny, W. D. (2013). Self-associations influence taskperformance through Bayesian inference. Front. Hum. Neurosci. 7:490. doi:10. 3389/fnhum.2013.00490

Brewer, J., Garrison, K., and Whitfield-Gabrieli, S. (2013). What about the "self" is processed in the posterior cingulate cortex? Front. Hum. Neurosci. 7:647. doi:10.3389/fnhum.2013.00647

Colton, G., Leshikar, E. D., and Gutchess, A. H. (2013). Age differences in neural response to stereotype threat and resiliency for self-referenced information. Front. Hum. Neurosci. 7:537. doi:10.3389/fnhum.2013.00537

Crone, J. S., Höller, Y., Bergmann, J., Golaszewski, S., Trinka, E., and Kronbichler, M. (2013). Self-related processing and deactivation of cortical midline regions in disorders of consciousness. Front. Hum. Neurosci. 7:504. doi:10.3389/fnhum. 2013.00504

D'Argembeau, A. (2013). On the role of the ventromedial prefrontal cortex in selfprocessing: the valuation hypothesis. Front. Hum. Neurosci. 7:372. doi:10.3389/ fnhum.2013.00372

Demertzi, A., Vanhaudenhuyse, A., Bredart, S., Heine, L., Di Perri, C., and Laureys, S. (2013). Looking for the self in pathological unconsciousness. Front. Hum. Neurosci. 7:538. doi:10.3389/fnhum.2013.00538
Flagan, T., and Beer, J. S. (2013). Three ways in which midline regions contribute to self-evaluation. Front. Hum. Neurosci. 7:450. doi:10.3389/fnhum.2013.00450

Gallagher, S. (2013). A pattern theory of self. Front. Hum. Neurosci. 7:443. doi:10.3389/fnhum.2013.00443

Knyazev, G. G. (2013). EEG correlates of self-referential processing. Front. Hum. Neurosci. 7:264. doi:10.3389/fnhum.2013.00264

Molnar-Szakacs, I., and Uddin, L. Q. (2013). Self-processing and the default mode network: interactions with the mirror neuron system. Front. Hum. Neurosci. 7:571. doi:10.3389/fnhum.2013.00571

Moran, J. M., Kelley, W. M., and Heatherton, T. F. (2013). What can the organization of the brain's default mode network tell us about self-knowledge? Front. Hum. Neurosci. 7:391. doi:10.3389/fnhum.2013.00391

Musholt, K. (2013). A philosophical perspective on the relation between cortical midline structures and the self. Front. Hum. Neurosci. 7:536. doi:10.3389/fnhum. 2013.00536

Nakao, T., Matsumoto, T., Morita, M., Shimizu, D., Yoshimura, S., Northoff, G., et al. (2013). The degree of early life stress predicts decreased medial prefrontal activations and the shift from internally to externally guided decision making: an exploratory NIRS study during resting state and self-oriented task. Front. Hum. Neurosci. 7:339. doi:10.3389/fnhum.2013.00339

Nejad, A. B., Fossati, P., and Lemogne, C. (2013). Self-referential processing, rumination, and cortical midline structures in major depression. Front. Hum. Neurosci. 7:666. doi:10.3389/fnhum.2013.00666

Qin, P., Grimm, S., Duncan, N. W., Holland, G., Guo, J. S., Fan, Y., et al. (2013). Selfspecific stimuli interact differently than non-self-specific stimuli with eyes-open versus eyes-closed spontaneous activity in auditory cortex. Front. Hum. Neurosci. 7:437. doi:10.3389/fnhum.2013.00437

Sandrone, S. (2013). Self through the mirror (neurons) and default mode network: what neuroscientists found and what can still be found there. Front. Hum. Neurosci. 7:383. doi:10.3389/fnhum.2013.00383

Sugiura, M. (2013). Associative account of self-cognition: extended forward model and multi-layer structure. Front. Hum. Neurosci. 7:535. doi:10.3389/fnhum.2013. 00535

Zhao, W., Luo, L., Li, Q., and Kendrick, K. M. (2013). What can psychiatric disorders tell us about neural processing of the self? Front. Hum. Neurosci. 7:485. doi:10.3389/fnhum.2013.00485

Received: 01 November 2013; accepted: 12 December 2013; published online: 25 December 2013.

Citation: Qin P, Duncan $N$ and Northoff $G$ (2013) Why and how is the self-related to the brain midline regions? Front. Hum. Neurosci. 7:909. doi: 10.3389/fnhum.2013.00909

This article was submitted to the journal Frontiers in Human Neuroscience.

Copyright (C) 2013 Qin, Duncan and Northoff. This is an open-access article distributed under the terms of the Creative Commons Attribution License (CC BY). The use, distribution or reproduction in other forums is permitted, provided the original author(s) or licensor are credited and that the original publication in this journal is cited, in accordance with accepted academic practice. No use, distribution or reproduction is permitted which does not comply with these terms. 